\title{
Study of the composition of hydrogenated silicon nitride SiNx:H for efficient surface and bulk passivation of silicon
}

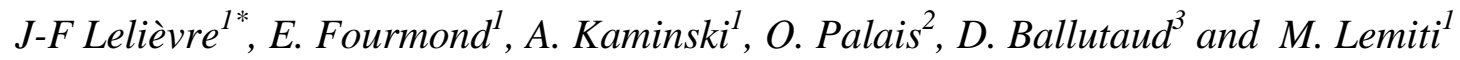 \\ ${ }^{1}$ Institut des Nanotechnologies de Lyon (INL-INSA), UMR CNRS 5270, INSA de Lyon, \\ Bât Blaise Pascal, 7 avenue Jean Capelle, 69621 Villeurbanne Cedex, France \\ 2 TECSEN, UMR CNRS 6122, Université Paul Cézanne-Aix-Marseille III, 13397 Marseille Cedex 20, France \\ ${ }^{3}$ GeMAC, 1 place Aristide Briand, 92195 Meudon Cedex, France
}

\begin{abstract}
:
This work is a contribution towards the understanding of surface and bulk passivation provided by hydrogenated silicon nitride, giving emphasis to $\mathrm{SiN}_{\mathrm{x}}: \mathrm{H}$ chemical structure and hydrogen desorption mechanism. Considering the deposition system used (Low Frequency PECVD), we report very low values of surface recombination velocity $S_{\text {eff. }}$ As-deposited Sirich $\mathrm{SiN}_{\mathrm{x}}: \mathrm{H}$ leads to the best results (n-type: $S_{\text {eff }}=4 \mathrm{~cm} / \mathrm{s}-$ p-type: $S_{\text {eff }}=14 \mathrm{~cm} / \mathrm{s}$ ). If fieldeffect passivation is always high whatever the $\mathrm{SiN}_{\mathrm{x}}: \mathrm{H}$ stoichiometry, it appears that the interface state density $\mathrm{D}_{\text {it }}$ is the key-parameter when considering surface passivation provided by $\mathrm{SiN}_{\mathrm{x}}: \mathrm{H}$ layers of different stoichiometries. After annealing, the surface passivation quality is drastically deteriorated for $\mathrm{Si}$-rich $\mathrm{SiN}_{\mathrm{x}}: \mathrm{H}$ whereas it is lightly improved for low refractive index $\operatorname{SiN}_{\mathrm{x}}: \mathrm{H}(\mathrm{n} \sim 2-2.1)$. The chemical analysis of the layers highlighted a high hydrogen concentration, whatever the $\mathrm{SiN}_{\mathrm{x}}: \mathrm{H}$ stoichiometry. However, the H-bond types involved as well as the hydrogen desorption kinetics are strongly dependent on the $\mathrm{SiN}_{\mathrm{x}}: \mathrm{H}$ composition. Furthermore, "N-rich" $\mathrm{SiN}_{\mathrm{x}}: \mathrm{H}$ appears to be denser and thermally more stable than Si-rich $\mathrm{SiN}_{\mathrm{x}}: \mathrm{H}$. Such a $\mathrm{SiN}_{\mathrm{x}}: \mathrm{H}$ layer is believed to induce the release of hydrogen in its atomic form, which would diffuse towards the substrate assisted by defects situated at the surface and in the bulk of the silicon substrate. Consequently, this would induce the minimisation of the $\mathrm{D}_{\mathrm{it}}$ and the increase of the bulk lifetime $\tau_{\mathrm{b}}$ after a high temperature step. On the other hand, Si-rich $\mathrm{SiN}_{\mathrm{x}}: \mathrm{H}$ (less dense and thermally less stable) would lead to molecular hydrogen desorption into the ambient. Moreover, a high fraction of Si-H bonds formed at the $\mathrm{SiN}_{\mathrm{x}}: \mathrm{H} / \mathrm{Si}$ interface during the $\mathrm{SiN}_{\mathrm{x}}: \mathrm{H}$ deposition would be broken by the high temperature process, increasing $\mathrm{D}_{\text {it }}$ and therefore $S_{\text {eff. }}$ The results are discussed and compared with the literature data reported for the different forms of PECVD reactors.
\end{abstract}

Keywords : Silicon Nitride, PECVD, passivation, solar cells

\section{Introduction}

During the industrial silicon solar cell fabrication process, the deposition of a thin a layer of hydrogenated silicon nitride $\mathrm{SiN}_{\mathrm{x}}: \mathrm{H}$ (abbreviated to $\mathrm{SiN}$ in the following) on the silicon substrate is of crucial importance. Indeed, the SiN layer acts as antireflective coating (ARC) and thus reduces considerably the optical losses [1]. Furthermore, its chemical composition, and particularly its high hydrogen content, leads to remarkable properties that allow to passivate (neutralize) defects situated at the surface and in the bulk of the silicon substrate,

\footnotetext{
* Corresponding author: Presently at the Instituto de Energía Solar, Avd. Complutense s/n, 28040 Madrid (Spain) - email: jflelievre@ies-def.upm.es - Tel: +34 - 914533555 -Fax: +34 - 915446341
} 
especially when considering multicrystalline samples (mc-Si) [1, 2, 3, 4]. Thanks to this single fabrication step, the solar cell efficiency is strongly increased. However, the origins of these interesting properties are still subjected to discussions, which is reinforced by the fact that a wide variety of $\mathrm{SiN}$ deposition systems are available.

In the photovoltaic area, $\mathrm{SiN}$ is currently deposited by Plasma-Enhanced Chemical Vapour Deposition (PECVD). As most of the photovoltaic research centres employ microwave $(\mu \mathrm{W})$ remote or high frequency (HF) direct PECVD reactors, very few results are published on the passivation properties of SiN elaborated by low frequency (LF) direct PECVD systems. The two first kind of reactor are known to provide a better surface passivation than the last one as the silicon substrate is not subjected to ion bombardment during deposition [5]. However, LFPECVD reactors are widely used in the industrial sector and some authors have reported that they lead to a more efficient hydrogenation of the silicon substrate [6, 7]. Indeed, the hydrogen contained in the SiN layer is known to be the origin of defect neutralization deep in the bulk of the silicon substrate, after the rapid high temperature annealing used for the industrial co-firing of the metallic contacts [1]. The atomic hydrogen $(\mathrm{H})$ diffusion from the $\mathrm{SiN}$ layer into the Si substrate would be governed by defect trapping mechanisms and would therefore have more effect on "bad" quality substrates (such as mc-Si) [4]. Furthermore, Sopori et al. [6] suggested that the damage induced by ion bombardment during LF-PECVD deposition would induce surface traps (Process Induced Traps - PITs) that would "stock" hydrogen and then redistribute it during annealing, resulting in an efficient bulk passivation. However, other authors have highlighted the important role of SiN density on the bulk passivation process [8]. A high density $\mathrm{SiN}$ would release less hydrogen than a material of lower density, but this key-element would diffuse in its atomic form, which is desirable for bulk passivation [9].

Another important aspect of $\mathrm{SiN}$ is its surface passivation properties. Indeed, the silicon surface presents a high density of dangling bonds, which is correlated to high recombination rates. The density and distribution of states introduced by these defects in the Si bandgap are expressed by the interface state density $\mathrm{D}_{\mathrm{it}}$. The Schokley-Read-Hall (SRH) recombination mechanism formalism can be reformulated in this case, considering recombination rates $\mathrm{U}_{\mathrm{s}}$ by surface unit [10]:

$$
U_{S}=\int_{E_{V}}^{E_{C}} \frac{v_{t h}\left(n_{s} p_{s}-n_{i}^{2}\right)}{n_{s}+n_{1}}+\frac{p_{s}+p_{1}}{\sigma_{p}(E)} D_{i t}(E) d E
$$

where $n_{i}$ is the intrinsic electron density, $v_{t h}$ is the thermal velocity of charge carriers and $n_{s}$ and $\mathrm{p}_{\mathrm{s}}$ are surface electron and hole concentrations, respectively. $\sigma_{\mathrm{n}}$ and $\sigma_{\mathrm{p}}$ represent the capture cross-sections of the considered defect for electron and holes, respectively. $\mathrm{n}_{1}$ (respectively $\mathrm{p}_{1}$ ) is defined as the electron (hole) density in the conduction band $\mathrm{E}_{\mathrm{C}}$ (valence band $E_{V}$ ) when the Fermi level $E_{F}$ coincide with the considered energy level E. Surface recombination velocity $\mathrm{S}$ is used to quantify these recombination rates and is defined as:

$$
U_{S}=S . \Delta n_{S}
$$

where $\Delta \mathrm{n}_{\mathrm{s}}$ is the concentration of carriers injected in the vicinity of the surface. Experimental results usually refer to effective surface recombination velocity $S_{\text {eff }}$, obtained by subtracting the volume contribution from the measured total sample lifetime $\tau_{\text {eff }}[11]$.

$\mathrm{SiN}$ exhibits the two fundamental mechanisms that can contribute to minimize the recombination processes at the silicon surface [1,3]. First, the deposition of such a layer 
induces the passivation of Si dangling bonds at the substrate surface and hence the reduction of the interface state density $\mathrm{D}_{\mathrm{it}}$. On the other hand, the high positive fixed charge density $\mathrm{Q}_{\mathrm{f}}$ reported for $\mathrm{SiN}$ allows reducing minority carrier concentration at the surface (hence $\mathrm{n}_{\mathrm{s}}$ or $\mathrm{p}_{\mathrm{s}}$ ) thanks to field-effect passivation [3, 12]. Indeed, a high density of positive fixed charges can induce an accumulation layer (respectively an inversion layer) at the surface of a moderately doped n-type (p-type) silicon substrate, which hence would repel the minority carriers from this high recombination region. In both cases, the silicon energy band bending induced by these charges leads to a strong reduction of the surface recombination velocity ${ }^{1}$. The $S_{\text {eff }}$ values reported, which were gathered by Cuevas et al. [11], are very low, indicating that $\mathrm{SiN}$ can provide better surface passivation properties than thermal $\mathrm{SiO}_{2}$ for moderately doped silicon [13, 14]. Here again, the SiN density appears to have a great influence on the passivation of the Si surface, before and after the co-firing step. Weeber et al. [15] reported that as-deposited Si-rich SiN provides the best surface passivation while after the high temperature step, N-rich (low refractive index) SiN leads to the best results. As the mass density has been identified as a decreasing function of the Si-content $[16,17]$, this parameter has become of great interest. It was also verified that a direct correlation exists between film mass density and Si-N bond concentration (which can be determined by FTIR measurements) [18]. Different studies showed that a low refractive index SiN layer $(\mathrm{n} \sim 2)$ with an optimum $\mathrm{Si}-\mathrm{N}$ bond density between $6-8 \times 10^{22}$ and $1.3 \times 10^{23} \mathrm{~cm}^{-3}$ provides the optimal surface (and bulk) passivation after the firing step [19, 20,21]. If these results are convincing, it is obvious that the temperature profile used will have also an important impact on the final passivation properties [21]. In addition, the deposition system and parameters may have an influence on these properties.

For SiN layers deposited by Low Frequency PECVD, the work presented here comforts the central role of the film mass density observed for other configurations of PEVD reactors. Furthermore, thanks to the structural and chemical characterizations of the SiN films, we will give emphasis to the hydrogen desorption process and its consequences on defect passivation. Different SiN stoichiometries were deposited thanks to a direct LF-PECVD reactor prototype (SEMCO-Engineering). In order to understand deeply the surface and bulk passivation properties of such SiN, we will first look closely at the SiN chemical structure, the hydrogen content and its desorption mechanism thanks to various characterization techniques. Then, we will present the results of the Capacitance-Voltage $(\mathrm{C}-\mathrm{V})$ measurements from which we could determine the densities $\mathrm{Q}_{\mathrm{f}}$ and $\mathrm{D}_{\mathrm{it}}$. Thanks to minority carrier lifetime measurements, we will subsequently demonstrate the good surface passivation properties provided by the $\mathrm{SiN}$ deposited with such a reactor. We will discuss on the origins of the passivation quality before and after a high temperature step. Finally, we will examine the bulk passivation process following such an annealing.

\section{Experimental}

After a standard cleaning of the silicon substrates, the SiN layers were deposited by direct LF-PECVD (440 kHz - SEMCO-Engineering). Only the SiN stoichiometry was modified, adjusting the ammonia-to-silane gas flow ratio $\mathrm{R}=\mathrm{NH}_{3} / \mathrm{SiH}_{4}$ while the temperature $\left(\mathrm{T}=370^{\circ} \mathrm{C}\right)$ and all the deposition parameters (pressure, plasma power, total gas flow) were maintained constant. For each stoichiometry, several samples were elaborated at the same time in order to be characterized by the various techniques used in this study.

For all the samples, the thickness, wavelength-dependant refractive index $n(\lambda)$ and

\footnotetext{
${ }^{1}$ Note that $S_{\text {eff }}$, defined by an effective surface at the limit of the quasi-neutral region, takes into account the recombination taking place at the surface as well as in the vicinity of the surface [11]
} 
extinction coefficient $\mathrm{k}(\lambda)$ of the different $\mathrm{SiN}$ films were deduced by spectroscopic ellipsometry (JobinYvon UVISEL), using Tauc-Lorenz dispersion model [22]. The refractive index $\mathrm{n}$ at $\lambda=605 \mathrm{~nm}$ will be used through this work to estimate the stoichiometry of the different $\mathrm{SiN}$ layers.

The influence of Rapid Thermal Annealing (RTA-ADDAX R1000) was systematically studied in order to simulate the co-firing of solar cell contacts. For this purpose, the samples were annealed at around $800^{\circ} \mathrm{C}$ during one second. The temperature profile was determined thanks to Transmission Line Model (TLM) measurements [23]: screen printing of industrial Ag paste was applied on standard ARC SiN/Si samples and the RTA parameters were adjusted for optimal contact resistance.

\section{a. XPS, SIMS, FTIR and TPD measurements}

The chemical composition $\mathrm{x}=[\mathrm{N}] /[\mathrm{Si}]$ of the films was evaluated by $\mathrm{X}$-photoelectron spectroscopy (XPS), carried out on the surface of five $\mathrm{SiN}\left(\mathrm{R}=\mathrm{NH}_{3} / \mathrm{SiH}_{4}=2 ; 3.5 ; 4.5 ; 7.7\right.$; 10) deposited on p-type CZ c-Si substrates $\left(\rho=10 \Omega . \mathrm{cm}-\mathrm{N}_{\mathrm{A}}=1.4 \times 10^{15} \mathrm{~cm}^{-3}\right)$. In order to detect the hydrogen concentration, SIMS measurements were done on the same samples. In parallel, FTIR measurements were performed in the transmission mode to investigate the evolution of $\mathrm{Si}-\mathrm{H}, \mathrm{N}-\mathrm{H}$ and $\mathrm{Si}-\mathrm{N}$ bond densities according to the stoichiometry of various $\mathrm{SiN}$ $(\mathrm{R}=2 ; 3.5 ; 4.5 ; 7.7 ; 10 ; 15 ; 30)$ deposited on double-side polished $10 \Omega$.cm p-type $\mathrm{CZ}$ c-Si. The effect of the RTA process on the H-content and H-bonds in the SiN films was also studied using samples elaborated at the same time and subsequently annealed. Finally, Temperature Programmed Desorption (TPD) measurements were carried out on three SiN samples $(\mathrm{R}=2 ; 7.7 ; 10)$ to investigate the temperature dependence of hydrogen releasing. In a vacuum environment, a temperature ramp was applied to the sample $\left(20^{\circ} \mathrm{C} / \mathrm{min}\right.$ from 20 to $810^{\circ} \mathrm{C}$ ) and a mass spectrometer allowed detecting the gas flow of molecular hydrogen $\mathrm{H}_{2}$ released from the $\mathrm{SiN}$ layer.

\section{b. C-V measurements}

In parallel, the electrical characteristics of SiN layers were obtained by dark capacitancevoltage $(\mathrm{CV})$ measurements at different frequencies $(1,10,100 \mathrm{kHz}$ and $1 \mathrm{MHz}$ using a HP4284A) performed on metal-insulator-semiconductor (MIS) structures: Al/SiN/Si/Al. For this purpose, single-sided $\mathrm{SiN}$ layers were deposited on $10 \Omega . \mathrm{cm}$ p-type $\mathrm{CZ}$ c-Si wafers $(\mathrm{R}=2 ; 3 ; 3.5 ; 6 ; 7.7 ; 10)$. Two $\mathrm{CZ}$ c-Si wafers were placed in the reactor for each run, one of which was RTA annealed before the deposition of aluminium by electron-beam evaporation on both sides of the structures. The MIS samples were then annealed at $400^{\circ} \mathrm{C}$ for 15 minutes under $\mathrm{H}_{2}$ in order to obtain ohmic contacts. The $\mathrm{CV}$ measurements were performed with applied voltages swept between the inversion and the accumulation modes and back to the inversion. They allowed determining the fixed charge density $\mathrm{Q}_{\mathrm{f}}$ in the $\mathrm{SiN}$ layer thanks to both the computation of the flat-band capacitance $\mathrm{C}_{\mathrm{FB}}$ and the Maserjian and Vincent method [24]. For some of the samples, the interface state density $\mathrm{D}_{\text {it }}$ could also be determined using the combined high-low frequency method [24]. However, due to hysteresis and leak effects, this computation was difficult and we prefer to present only the few unambiguously obtained values.

\section{c. Lifetime measurements}

For lifetime measurements, $\mathrm{SiN}$ layers were deposited by direct LF-PECVD $(\mathrm{R}=2 ; 2.5$; $3.5 ; 6 ; 7.7 ; 10)$ on both surfaces of $5 \Omega . c m$ p-type and n-type FZ c-Si wafers as well as on 
textured $2.5 \Omega$.cm p-type mc-Si substrates. The mc-Si samples were taken from consecutive wafers from the same ingot and present the same grain distribution, from which we can suppose an equal distribution of initial bulk lifetime $\tau_{\mathrm{b}}$. Lifetime measurements were carried out using the PhotoConductance Decay (PCD) method developed by Sinton and Cuevas [25], in both the transient and quasi-steady state measurement modes. Under the assumption that all studied FZ c-Si samples have equally high values for the bulk lifetime $\left(\tau_{\mathrm{b}}\right)$, the extracted values of the effective lifetime $\left(\tau_{\text {eff }}\right)$ can be used as a measure of the surface passivation quality of the different SiN layers. Indeed, if we consider a uniform carrier generation in the silicon wafer $\left(\Delta \mathrm{n}=\Delta \mathrm{n}_{\mathrm{s}}\right)$, effective lifetime can be expressed as [26]:

$$
\frac{1}{\tau_{\text {eff }}} \approx \frac{1}{\tau_{b}}+\frac{2 S_{\text {eff }}}{W}
$$

The usual hypotheses made on $\tau_{\mathrm{b}}$ lead to generally overestimated values of $\mathrm{S}_{\text {eff. }}$ This simplified equation can be used with an error $<4 \%$ for $S_{\text {eff }}$ lower than $250 \mathrm{~cm} / \mathrm{s}$ for such c-Si substrates [27].

The results were confirmed independently by the microwave phase-shift ( $\mu \mathrm{W}$-PS) technique [28], giving $S_{\text {eff }}$ and $\tau_{\mathrm{b}}$ cartographies of the studied samples. The latter values were found with a $200 \mu \mathrm{m}$ spatial resolution and for an injection level $\Delta \mathrm{n}$ of $7 \times 10^{14} \mathrm{~cm}^{-3}$. Such a value allows working at low injection level while avoiding measurement artefacts induced by material defect (especially when considering mc-Si substrates) [29]. Furthermore, such $\Delta \mathrm{n}$ is equivalent to the carrier photogeneration under standard AM1.5G illumination in an ordinary silicon substrate of thickness $\mathrm{W}=300 \mu \mathrm{m}$ and mean lifetime $\tau=80 \mu \mathrm{s}$ [26]. Hence, $\tau_{\text {eff }}$ results are given in this work for this $\Delta \mathrm{n}=7.10^{14} \mathrm{~cm}^{-3}$, although they do not correspond to the highest values. All the samples were then annealed and lifetime measurements were performed again.

\section{SiN Stoichiometry and hydrogen desorption}

\section{a. SiN stoichiometry}

For two of the samples studied by XPS ( $\mathrm{R}=2 ; 7.7)$, the chemical composition of the SiN coatings was determined along the full thickness of the films thanks to layer abrasion. This showed a stable $\mathrm{x}=[\mathrm{N}] /[\mathrm{Si}]$ ratio through the whole width of the $\mathrm{SiN}$ layers, which indicates a good SiN structural homogeneity. These measurements demonstrated as well that a thin layer of silicon oxynitride $\mathrm{SiO}_{\mathrm{x}} \mathrm{N}_{\mathrm{y}}(<2 \mathrm{~nm})$ is formed at the $\mathrm{SiN} / \mathrm{Si}$ interface, which is due to silicon oxidation during sample loading into the PECVD reactor.

The $\mathrm{x}$ ratio was evaluated $5 \mathrm{~nm}$ deep in the different $\mathrm{SiN}$ layers, giving $\mathrm{x}=0.35 ; 0.49$; $0.59 ; 0.78$ and 0.81 for the films obtained with a gas flow ratio of $\mathrm{R}=2 ; 3.5 ; 4.5 ; 7.7$ and 10 , respectively. As expected, the silicon content decreases as the gas flow ratio is increased. However, these results indicate a high silicon excess for all the SiN layers. It is worth noting here that the $\mathrm{SiN}$ film obtained for $\mathrm{R}=7.7$ has a refractive index $n(605 \mathrm{~nm})=2.03$ close to that of stoichiometric $\mathrm{Si}_{3} \mathrm{~N}_{4}(\mathrm{n}[605 \mathrm{~nm}]=2.04$ [30]), for which $\mathrm{x}=1.33$. The difference between the $[\mathrm{N}] /[\mathrm{Si}]$ ratio and the optical properties is believed to be due to hydrogen and void incorporation in the PECVD films, which produces a variation of the optical constants. This could be attributed to the low frequency plasma process, as it has been already observed [31, 32]: the composition of the $\mathrm{SiN}$ films remains far from the stoichiometry $(\mathrm{x}=1.33)$. The dissociation and activation of the reactive species issued from ammonia needs much more energy than for the silane radicals $[33,34]$. For the deposition temperatures considered, and 
since low frequency is used for plasma excitation, the $\mathrm{NH}_{3}$ reactive species density is believed to stay low in spite of the increasing of the $\mathrm{NH}_{3}$ gas flow.

With the deposition conditions used in this work, it seems difficult to obtain $\mathrm{x}$ values greater than 0.9. However, the large silicon excess produced during the plasma process gives rise to interesting layer properties for such low refractive $\mathrm{SiN}$ : indeed, we have previously demonstrated the intrinsic formation of silicon nanocrystals (nc-Si) in the amorphous $\mathrm{SiN}$ matrix for a tight range of $\mathrm{SiN}$ stoichiometries $(0.7<\mathrm{x}<0.9)[35,36]$. These nanostructures (ns-Si) could be useful for the development of all-silicon tandem solar cells [37]. For the structural composition of the SiN, we thus forward the model proposed by Gritsenko et al. [38] for the chemical structure of their SiN films obtained by Low Pressure CVD. Basically, it considers the formation of ns-Si (in the crystalline form or not) in the SiN matrix which results in a non-uniform compositional distribution. As it was verified with our XPS spectra, as well as with TEM observations [36], this model can be seen as an intermediate solution between the Random Bonding Model (RBM) of H.R. Philipp [39] and the Stoichiometric Statistical Model (SSM) [40]: the matrix would be a mixture of $\mathrm{Si}$ and $\mathrm{Si}_{3} \mathrm{~N}_{4}$ clusters (composed respectively by $\mathrm{Si}_{-} \mathrm{Si}_{4}$ and $\mathrm{Si}-\mathrm{N}_{4}$ tetrahedrons), separated by a random bonded intermediate $\mathrm{SiN}_{\mathrm{y}} \mathrm{H}$ matrix. In spite of this atomic-scale heterogeneity, the films are homogeneous in composition within their whole thickness.

It is interesting to link the $\mathrm{SiN}$ composition to the refractive index, as the latter is often used as a measure of the Si-content of the layers. The equation proposed by Bustarret et al. [41] gave results very far from the experimental ones. This shows that, in our case, hydrogen and porosity in the SiN layer cannot be neglected. The fact that this equation was successfully used by other authors $[12,20]$ points out the difference in structural composition for $\mathrm{SiN}$ obtained with distinct deposition systems, especially considering the frequency of the plasma excitation. Most of the SiN passivation results published in the literature involve direct high frequency and remote $\mu \mathrm{W}$ PECVD reactors. In these equipments, the Si substrate is not subjected to ion bombardment and an inert gas such as Argon is usually added to the plasma in order to facilitate the $\mathrm{NH}_{3}$ dissociation. This is believed to have a strong impact on the $\mathrm{SiN}$ stoichiometry, density and hydrogen content, and subsequently on the optical constants of the material. To link stoichiometry and refractive index, we thus used an empirical relation, inspired from the linear dependence of $n$ and 1/x observed by S. Dauwe [42]:

$$
\mathrm{n}=1.22+0.61(1 / \mathrm{x})
$$

As expected, this relation is different from the one found by S. Dauwe but it gives a good estimation of the stoichiometry of the SiN deposited with our LF-PECVD reactor (Figure 1). Furthermore, the results we have reported elsewhere [32] with an other LF-PECVD reactor $(40 \mathrm{kHz}-$ Centrotherm) are in good agreement with this equation. When comparing SiN obtained with different deposition techniques, the complete complex optical index $\mathrm{N}=\mathrm{n}+\mathrm{ik}$ should be taken into account. Indeed, the extinction coefficient $\mathrm{k}$ at low wavelengths gives reliable information on the $\mathrm{Si}$-content of the $\mathrm{SiN}$ layer, as we have already suggested elsewhere $[43,44]$.

\section{b. Hydrogen content}

It seems interesting to evaluate the hydrogen content and its evolution according to the $\mathrm{SiN}$ stoichiometry. The literature reports H-concentration in the range of $\sim 10^{22} \mathrm{~cm}^{-3}$, whatever the PECVD reactor configuration used [5, 6, 45], corresponding to 20 to 30 at $\%$. Our SIMS measurements showed good chemical homogeneity and high hydrogen content for all the samples studied. As the chemical structure of the $\mathrm{SiN}$ is different from one sample to another, 
it appears difficult to find a reliable reference for accurate hydrogen concentration determination. However, a relative comparison is still possible: Figure 2 shows the hydrogen spectra for a $\mathrm{Si}$ - and a "N-rich" $\mathrm{SiN}$ (respectively $\mathrm{R}=2$ and $\mathrm{R}=7.7$ ), adjusting at the same level their respective $\mathrm{Si}$ signal ( $\mathrm{Si} 28)$ in the c-Si substrate. The corresponding high hydrogen profiles reveal a really close $\mathrm{H}$-concentration for these distinct materials $(\mathrm{n}=2.98 / \mathrm{x}=0.35$ and $n=2.03 / x=0.78$ respectively). As it will be discussed below, the relative $\mathrm{H}$-amount in the SiN layer does not appear to be a key parameter for surface and bulk passivation. For this purpose, the study of hydrogen release and diffusion mechanisms gives more valuable information.

FTIR measurements allow to characterize the bonds involved in the material, and eventually to determine bond densities and thus hydrogen concentration thanks to the method developed by Landford and Rand [16]. We chose not to apply this widely used technique because the employed constants values need first to be calibrated as they seem controversial and dependent on the SiN composition [46]. Nevertheless, these measurements give interesting qualitative information on the involved bonds, consistent with what is reported in the literature. First, the large band centred around $830 \mathrm{~cm}^{-1}$ is attributed to the Si-N bond (stretching mode). Its asymmetry reveals the contribution of several modes: $\mathrm{SiN}_{\mathrm{n}}$ (stretching mode $\left.-790 \mathrm{~cm}^{-1}\right) ; \quad\left(\mathrm{Si}-\mathrm{H}_{2}\right)_{\mathrm{n}}$ (wagging and bend-scissors $-845 \mathrm{~cm}^{-1}$ and $\left.890 \mathrm{~cm}^{-1}\right) ; \mathrm{N}-\mathrm{Si}_{3}$ (asymmetric stretching mode $-850 \mathrm{~cm}^{-1}$ ); $\mathrm{H}-\mathrm{Si}-\mathrm{N}_{3}$ (stretching mode $-1020 \mathrm{~cm}^{-1}$ ) [47]. Note that these values and their attribution can vary from one author to another. In this region, there is also a feature which is hydrogen related, namely the $\mathrm{N}-\mathrm{H}$ bending band near $1180 \mathrm{~cm}^{-1}$ [48]. Additionally, absorption bands for the $\mathrm{N}-\mathrm{H}$ stretching mode are observed near $3320 \mathrm{~cm}^{-1}$ (see Figure 3). It can clearly be seen that the N-H bond concentration increases when the Ncontent in the SiN film is higher. Then, for $\mathrm{R}<7.7$, the $\mathrm{N}-\mathrm{H}$ band was hardly detectable. The $\mathrm{Si}-\mathrm{H}$ stretching modes were observed near $2180 \mathrm{~cm}^{-1}$ for the $\mathrm{SiN}$ coatings with $\mathrm{R}<10$, with peak position varying according to Si-content as described by Giorgis et al. [49]. As the surface under the curve is proportional to the total bond density, these measurements support that the film density increases when the Si-content decreases, as reported in the literature [16, 17]. Furthermore, the results show that the $\mathrm{N}-\mathrm{H}$ and $\mathrm{Si}-\mathrm{N}$ bond concentrations are increasing functions of the gas flow ratio $\mathrm{R}$ (Si-content decreases). In contrast, the $\mathrm{Si}-\mathrm{H}$ bond concentration decreases as the silicon content of the $\mathrm{SiN}$ films is reduced. Hence, there is strong evidence that there is a preferential tendency for the formation of strong $\mathrm{Si}-\mathrm{N}$ and $\mathrm{N}-\mathrm{H}$ bonds in the "N-rich" SiN films.

\section{c. Hydrogen desorption}

The samples were then annealed at around $800^{\circ} \mathrm{C}$ for 1 second. Annealing $\mathrm{SiN}$ at high temperatures is known to induce the release of hydrogen from the layer, which will passivate defects in the bulk for well chosen annealing temperature and time, breaking first $\mathrm{Si}-\mathrm{H}$ bonds $(\sim 3.1 \mathrm{eV})$, then $\mathrm{N}-\mathrm{H}$ bonds $(\sim 4.1 \mathrm{eV})$ [17]. The high temperature step induced hardly detectable change of the FTIR band amplitudes related to Si-H and N-H bonds. Similarly, SIMS measurements showed no significant change of the H-content in the SiN layer after such a RTA process. The quantity of hydrogen released is too small to be detected by SIMS, as the detection threshold for $\mathrm{H}$ is around $10^{18} \mathrm{~cm}^{-3}$. This observation point out the limits of the techniques used to detect hydrogen. However, some authors demonstrated that only a small part of the hydrogen diffuse out of the $\mathrm{SiN}$ layer during this kind of short temperature treatment $[17,50]$. The desorbed quantity $\left(\sim 10^{15}-10^{16} \mathrm{~cm}^{-3}\right)$ seems therefore difficult to detect. Furthermore, Jiang et al. [50] provided evidence that only a tenth of a percent of the hydrogen that is released diffuses effectively in the silicon substrate. If this quantity is small, it is nonetheless sufficient to affect the electrical activity of dislocations and impurities contained 
in the $\mathrm{Si}$ substrate, and thus increase the bulk lifetime as it will be demonstrated in the following.

On the other hand, the high temperature step affected clearly the optical constants of Sirich $\mathrm{SiN}$. The results, presented elsewhere [32], show that the refractive index as well as the extinction coefficient increase significantly for Si-rich $\mathrm{SiN}$ films $(n>2.15)$ while the optical constants remain unchanged for "N-rich" material $(n<2.15)$. This can be correlated to the FTIR measurements showing that, for Si-rich $\mathrm{SiN}$, the maximum of the $\mathrm{Si}-\mathrm{H}$ band is shifted after the RTA process, indicating local reorganization of the bonds and densification of the layer. This shows that the material is thermally more stable when involving a higher fraction of nitrogen.

Figure 4 displays the evolution of the hydrogen flow released during TPD measurements for three distinct $\mathrm{SiN}$ stoichiometries: $\mathrm{R}=2(\mathrm{n}=2.98-\mathrm{x}=0.35) ; \mathrm{R}=7.7 \quad(\mathrm{n}=2.03-$ $\mathrm{x}=0.78) ; \mathrm{R}=10(\mathrm{n}=1.98-\mathrm{x}=0.81)$. All the films begin to release hydrogen at around $400^{\circ} \mathrm{C}$. For the Si-richest $\mathrm{SiN}(\mathrm{R}=2)$, the hydrogen desorption is much faster than for the other samples. Indeed, the gas flow increases drastically from 440 to $680^{\circ} \mathrm{C}$ then decreases as rapidly from 680 to $810^{\circ} \mathrm{C}$. At this temperature, the layer appears to have released the quasitotality of its hydrogen. On the other hand, H-exodiffusion from "N-rich" SiN is much slower: at $810^{\circ} \mathrm{C}$ the gas flow still increases, which means that a non-negligible amount of hydrogen remains in the film. For the studied samples, the hydrogen released at temperature as low as $440^{\circ} \mathrm{C}$ is thus attributed to the breaking of $\mathrm{Si}-\mathrm{H}$ bonds. These results show as well that $\mathrm{Si}-\mathrm{H}$ bonds are broken at around $650^{\circ} \mathrm{C}$ and that $\mathrm{N}-\mathrm{H}$ bonds still resist to temperatures as high as $800^{\circ} \mathrm{C}$. For the two "N-rich" samples $(\mathrm{R}=10$ and 7.7$)$, the $\mathrm{H}$ desorption kinetics are similar, although their $\mathrm{N}-\mathrm{H}$ and $\mathrm{Si}-\mathrm{H}$ bond densities are different (Figure 3). Nevertheless, their respective stoichiometries and $\mathrm{Si}-\mathrm{N}$ bond densities are really close, which indicates similar film densities. Dekkers et al. [9] showed that the diffusion coefficient of hydrogen decreases for increasing SiN density. Hence, the TPD results confirm that hydrogen diffusion and effusion is made easier in a Si-rich SiN, while it is slowed for "N-rich" SiN. The SiN density appears to be a key-parameter of the H-diffusion kinetics.

\section{Surface Passivation}

\section{a. Capacitance-Voltage measurements}

The positive fixed charge density $\mathrm{Q}_{\mathrm{f}}$ in the different $\mathrm{SiN}$ layers was determined thanks to $\mathrm{C}-\mathrm{V}$ measurements. These charges correspond to electrical defects which charge state cannot vary in function of the electrical polarization of the MIS structure. For the SiN, it is generally admitted that the fixed charges are situated in the first $20 \mathrm{~nm}$ of the layer [3]. Indeed, the constraints induced in this region give rise to a high defect density that can be electrically charged.

An example of $\mathrm{C}-\mathrm{V}$ curve is displayed in Figure 5 for $\mathrm{SiN}$ with $\mathrm{n}=1.98(\mathrm{R}=10)$. The high flat band voltages obtained (here $\mathrm{V}_{\mathrm{FB}}=-22.8 \mathrm{~V}$ ) indicate high positive fixed charge densities (here $\mathrm{Q}_{\mathrm{f}}=7.1 \times 10^{12} \mathrm{~cm}^{-2}$ ). The Si dangling bond is the dominant deep defect in SiN films. Its predominant configuration is $\cdot \mathrm{Si} \equiv \mathrm{N}_{3}$ (the so-called $\mathrm{K}$ centre), which create a high density of states in the middle of the gap $[12,51,52]$. The $\mathrm{K}$ centres, in their stable form $\mathrm{N}_{3} \equiv \mathrm{Si}+\left(\mathrm{K}^{+}\right.$ centres) contribute primarily to the positive charge $\mathrm{Q}_{\mathrm{f}}$. The Nitrogen dangling bond $=\mathrm{N}^{-}$can only be observed for stoichiometric and over-stoichiometric $\operatorname{SiN}(x>1.33)$ [51]. Their contribution to the total charge can be neglected in our case $(\mathrm{x}<0.81)$. On the other hand, defects introduced by the thin interface $\mathrm{SiO}_{\mathrm{x}} \mathrm{N}_{\mathrm{y}}$ layer $(<2 \mathrm{~nm})$ could increase $\mathrm{Q}_{\mathrm{f}}$. The additional positive fixed charge would be generated by the following configurations: $\mathrm{O}_{3} \equiv \mathrm{Si}$, $\mathrm{O}_{2} \mathrm{~N} \equiv \mathrm{Si} \cdot$ or $\mathrm{ON}_{2} \equiv \mathrm{Si} \cdot$ [3]. The important counter-clockwise hysteresis effect observed for all 
the samples can be attributed to slow states situated near the interface (1 to $3 \mathrm{~nm}$ ), with a capture cross-section decreasing as these defects are situated farther from the interface [24]. The $\mathrm{K}$ centres are amphoteric with three charge states $(+, 0,-)$ and are neutral when one electron is attached [51]. Hence, a strong negative polarization can induce electron emission from $\mathrm{K}^{\circ}$ and $\mathrm{K}^{-}$centres situated near the interface. As these charges are created with the polarization, we will not consider their contribution to the total $\mathrm{Q}_{\mathrm{f}}$.

For all the studied samples (Figure 6), the fixed charge density are greater than $10^{12} \mathrm{~cm}^{-2}$, which is very high in comparison with values reported for silicon oxide $\left(\sim 10^{10}\right.$ to $\left.10^{11} \mathrm{~cm}^{-2}\right)$ [2]. $\mathrm{Q}_{\mathrm{f}}$ increases as the N-content of the SiN layer increases. This is consistent with the fact that the Si dangling bonds come to be more and more in their $\mathrm{K}^{+}\left(\mathrm{N}_{3} \equiv \mathrm{Si}+\right)$ configuration. The simultaneous increase of the hysteresis effect with the N-content indicates an increasing slow states density, which hence confirms an increase of the $\mathrm{K}$ centre density. Consequently, for the $\mathrm{SiN}$ stoichiometries studied in this work $(0.35<\mathrm{x}<0.81)$, we can suppose that the fieldeffect passivation will be more efficient for N-rich SiN layers. However, the values obtained for the interface state density $D_{i t}$ are high $\left(D_{i t}=3 \times 10^{11} \mathrm{~cm}^{-2} \cdot \mathrm{eV}^{-1}\right.$ for the example shown in Figure 5) in comparison with values reported for silicon oxide $\left(\sim 10^{10} \mathrm{~cm}^{-2} \cdot \mathrm{eV}^{-1}\right)$ [2]. Even if the field-effect passivation should be efficient for all the stoichiometries, the high interface state density could affect it by increasing the recombination probability.

After the RTA process, $\mathrm{Q}_{\mathrm{f}}$ decreases for all the samples (Figure 6). This can be attributed to a neutralization of dangling bonds situated in the $\mathrm{SiN}$ (K centres) close to the interface by the hydrogen diffused from the $\mathrm{SiN}$ layer itself. Nevertheless, the final $\mathrm{Q}_{\mathrm{f}}$ values are still very high $\left(>10^{12} \mathrm{~cm}^{-2}\right)$ and the field-effect passivation should still be efficient. Furthermore, the high temperature step induced a strong reduction of $D_{\text {it }}$ from $\sim 10^{11}$ to $\sim 10^{10} \mathrm{~cm}^{-2} . \mathrm{eV}^{-1}$ for the samples with $R=7.7(n=2.03)$ and $R=10(n=1.98$ - the other values were not exploitable $)$. As it will be developed in the following, this can be attributed to hydrogen passivation of surface silicon dangling bonds. This mechanism will be studied carefully as it plays an important role in the surface passivation process.

\section{b. Surface passivation : as-deposited SiN layers}

The evolution of effective minority carrier lifetime $\tau_{\text {eff }}$ in function of injection level $\Delta \mathrm{n}$ is presented in Figure 7 for SiN layers deposited on n-type c-Si wafers. Table 1 shows the corresponding $\tau_{\text {eff }}$ values $\left(\Delta \mathrm{n}=7 \times 10^{14} \mathrm{~cm}^{-3}\right)$ for the n-type and p-type samples. It also displays the extracted surface recombination velocities $S_{\text {eff }}$ assuming infinite bulk lifetime, which gives the upper limit of $S_{\text {eff }}$ (Eq. 3).

Firstly, for a same SiN stoichiometry, surface passivation is better achieved on n-type than on p-type silicon wafers. Following Eq. (1), the surface recombination rate is dependent of $\mathrm{Q}_{\mathrm{f}}$ (through $\mathrm{n}_{\mathrm{s}}$ and $\mathrm{p}_{\mathrm{s}}$ ) and $\mathrm{D}_{\mathrm{it}}$, as we have already seen. Another important parameter which affects $S_{\text {eff }}$ is the substrate doping level (through $n_{s}, p_{s}, n_{1}$ and $p_{1}$ ). Here, the doping difference is too small to explain the better results obtained on n-type c-Si substrates: $\mathrm{N}_{\mathrm{A}}=2.8 \times 10^{15} \mathrm{~cm}^{-3}$ (p-type) and $\mathrm{N}_{\mathrm{D}}=9.2 \times 10^{14} \mathrm{~cm}^{-3}$ (n-type). Furthermore, surface recombination velocity depends strongly on the capture cross-sections $\sigma_{\mathrm{n}}$ and $\sigma_{\mathrm{p}}$. The better surface passivation obtained for n-type c-Si (see Fig.2) could be explained by a large capture cross-section ratio of minority to majority charge carriers $\left(\sigma_{\mathrm{n}} / \sigma_{\mathrm{p}} \sim 100\right.$ at midgap). This would lead to more critical surface passivation for p-type silicon [31], although values for $\sigma_{\mathrm{n}} / \sigma_{\mathrm{p}}$ may be discussed [52].

In all cases, the $S_{\text {eff }}$ values obtained are very low (see Table 1) and are a good result in comparison with values reported in the literature for low frequency PECVD reactors. Effective lifetime as high as $3.62 \mathrm{~ms}$ was found for the Si-richest SiN layer deposited on ntype c-Si, corresponding to $S_{\text {eff }}$ as low as $4 \mathrm{~cm} / \mathrm{s}$. With this kind of reactor, Schuurmans 
obtained an optimal value of $45 \mathrm{~cm} / \mathrm{s}$ for a FZ p-type c-Si with resistivity $\rho=1.9 \Omega . c \mathrm{~cm}$ [27]. Schmidt and Aberle reported values of $30 \mathrm{~cm} / \mathrm{s}$ and $100 \mathrm{~cm} / \mathrm{s}$ for FZ p-type samples with respective resistivities of $20 \Omega$.cm and $1.5 \Omega . \mathrm{cm}$ [52]. For n-type substrates $(\rho=10 \Omega . \mathrm{cm})$, they obtained $S_{\text {eff }}=19 \mathrm{~cm} / \mathrm{s}$. Even if our $\tau_{\text {eff }}$ results remain lower than the ones reported for direct high frequency and remote PECVD reactors $[11,53]$, the surface passivation quality of the $\mathrm{SiN}$ deposited with our LF-PECVD reactor is clearly satisfying, despite the fact that the $\mathrm{Si}$ substrate is subjected to ion bombardment during the SiN deposition.

Looking at different $\mathrm{SiN}$ stoichiometries, $\tau_{\text {eff }}$ increases when the Si-content of the $\mathrm{SiN}$ layer is increased for both the n- and p-type FZ c-Si samples (Table 1). This is consistent with results reported in the literature for different PECVD reactor configurations [53]. It should be noticed that Schmidt and Kerr [54] obtained an optimal effective lifetime for "stoichiometric" $\mathrm{SiN}$ ( $\mathrm{n}=1.9$ - HF-PECVD), which they attributed to the use of diluted silane $\left(5 \%\right.$ in $\mathrm{N}_{2}$ ) as precursor gas. Hence, the surface passivation properties of as-deposited $\mathrm{SiN}$ seem to be strongly dependent on the deposition system and parameters.

Figure 8 shows the evolution of $\tau_{\text {eff }}$ according to the refractive index $n$ of the different $\mathrm{SiN}$ layers, before and after the annealing. This graph displays as well the results obtained with mc-Si substrates: before annealing, the evolution of $\tau_{\text {eff }}$ according to the refractive index is comparable with the one observed with monocrystalline substrates. However, $\tau_{\text {eff }}$ is a global measure that integrates $S_{\text {eff }}$ and $\tau_{\mathrm{b}}$ and it becomes more difficult to identify the relative contribution of each parameter in the case of mc-Si samples. Our PCD measurements were completed by $S_{\text {eff }}$ and $\tau_{\mathrm{b}}$ cartographies obtained by the $\mu \mathrm{W}$-PS method. Figures 9 and 10 show the results for the mc-Si substrates coated by Si-rich $\mathrm{SiN}(\mathrm{R}=2-\mathrm{n}=2.98)$ and "N-rich" $\mathrm{SiN}$ ( $\mathrm{R}=6-\mathrm{n}=2.08)$, before and after annealing. $S_{\text {eff }}$ and $\tau_{\mathrm{b}}$ values are heterogeneous as expected for mc-Si samples: $S_{\text {eff }}$ varies for example between few $\mathrm{cm} . \mathrm{s}^{-1}$ and more than $1000 \mathrm{~cm} . \mathrm{s}^{-1}$ for as-deposited layers (Figure 9.a). Better results are clearly obtained when the Si-rich silicon nitride is used as passivation layer, with a mean value of $S_{\mathrm{m}_{-}}=215 \mathrm{~cm} . \mathrm{s}^{-1}$ and $S_{\text {eff }}$ remaining lower than $150 \mathrm{~cm} \cdot \mathrm{s}^{-1}$ on an important part of the sample surface. On the other hand, $S_{\text {eff }}$ is always higher than $150 \mathrm{~cm} . \mathrm{s}^{-1}$ for the "N-rich" sample. These results are in agreement with the ones obtained with the FZ c-Si substrates. They confirm that, after LFPECVD deposition, the different SiN layers provide good surface passivation and that Si-rich $\mathrm{SiN}$ leads to the lowest surface recombination velocities.

\section{c. Surface passivation after a high temperature step}

After a high temperature step (simulating the co-firing of solar cell contacts), $\tau_{\text {eff }}$ decreases strongly for c-Si samples coated with $\mathrm{Si}$-rich $\mathrm{SiN}$ (Figure 8). If we assume that $\tau_{\mathrm{b}}$ remains

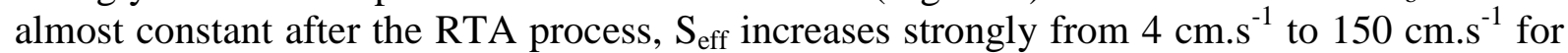
the n-type substrate coated with the Si-richest $\mathrm{SiN}(\mathrm{R}=2-\mathrm{n}=2.98)$. On the other hand, the surface passivation quality provided by the "N-rich" alloys $(\mathrm{R}=10,6,7.7)$ hardly changes and even increases. An identical behaviour was found for mc-Si samples (Figures 8 and 9.b). The cartographies show that the RTA process induced a strong deterioration of the surface passivation quality provided by the $\mathrm{Si}$-rich $\mathrm{SiN}(\mathrm{R}=2)$, with $\mathrm{S}_{\text {eff }}$ greater than $700 \mathrm{~cm} \cdot \mathrm{s}^{-1}$ for a large part of the analyzed surface. The entire surface seems affected and there is no clear correlation between the initial and the final $S_{\text {eff }}$ value. On the other hand, $S_{\text {eff }}$ is strongly reduced for the "N-rich" sample $(\mathrm{R}=6): S_{\text {eff }}$ is lower than $150 \mathrm{~cm} \cdot \mathrm{s}^{-1}$ on a large part of the substrate area, which results in a low average value $\left(S_{m}=350 \mathrm{~cm} . \mathrm{s}^{-1}\right)$. It is worth noting however that the regions of the mc-Si wafer which exhibit high surface recombination velocities (> $700 \mathrm{~cm} . \mathrm{s}^{-1}$ ) appear difficult to improve. Nevertheless, for $\mathrm{n}$ - and p-type Si samples, the best surface passivation after annealing is obtained for SiN with low refractive index $(\mathrm{n} \sim 2-2.1)$. 


\section{d. Discussion}

Our results show a high surface passivation quality for as-deposited samples, with $\mathrm{S}_{\text {eff }}$ decreasing with the Si-content of SiN. At first, this seems in contradiction with the C-V results from which field-effect passivation was supposed to be less efficient in this case. However, it should be reminded that $Q_{f}$ is very high for all the stoichiometries $\left(>10^{12} \mathrm{~cm}^{-2}\right)$ and that such fixed charge densities should provide a good field-effect passivation regardless the stoichiometry. On the other hand, Schmidt and Aberle [52] suggested that $\mathrm{Q}_{\mathrm{f}}$ must be drastically reduced to $\sim 10^{11} \mathrm{~cm}^{-2}$ under illumination (PCD measurements case) in comparison with the values determined by dark $\mathrm{C}-\mathrm{V}$ measurements: illumination could lift the quasiFermi level $\Phi_{\mathrm{n}}$ above the energy level of the $\mathrm{K}^{+}$centres, leading to their neutralization. This could make the field-effect passivation less efficient under illumination. Whatever this issue is, the interface state density $\mathrm{D}_{\text {it }}$ appears to be a key-parameter when comparing different $\mathrm{SiN}$ stoichiometries. For Si-rich $\mathrm{SiN}$, an important flow of the very reactive silane $\left(\mathrm{SiH}_{4}\right)$ during the PECVD process could provide more H-radicals to the plasma. This would contribute to an efficient neutralization of interface states thanks to $\mathrm{Si}-\mathrm{H}$ bonds, and thus reduce the corresponding $\mathrm{D}_{\mathrm{it}}$. Mäckel and Lüdemann [12] consider that the Si-H bond density in the SiN layer is a quality indicator of surface passivation. As it was demonstrated thanks to FTIR measurements, Si-rich SiN exhibits a higher Si-H bond density, which can be correlated to a better passivation of the dangling bonds at the silicon surface. Furthermore, we can suppose that such layers induce less constraint with the silicon substrate, and hence less surface defects. Hence, the high $\mathrm{K}^{+}$centres density in "N-rich" SiN appears to be not sufficient enough to compensate the higher interface state density.

In contrast, after a high temperature step, the best surface passivation is provided by low refractive index SiN. The chemical and structural analysis of these SiN layers showed that they are denser and thermally more stable than Si-rich samples. The hydrogen desorption kinetics are also different according to the SiN stoichiometry, Si-rich SiN releasing faster a higher hydrogen concentration than "N-rich" SiN. According to Dekkers et al. [9], a low density material would induce the release of hydrogen in the molecular form $\left(\mathrm{H}_{2}\right)$. On the contrary, a denser SiN would make the hydrogen desorption slower but its atomic form would be advantaged. We can thus suppose that the hydrogen is widely released in its molecular form out of the sample in the case of Si-rich SiN, with a more "opened" structure. Furthermore, a great part of the $\mathrm{Si}-\mathrm{H}$ bonds at the $\mathrm{SiN} / \mathrm{Si}$ interface would be broken by the high temperature step, leading to the increase of $D_{\text {it }}$ and $S_{\text {eff. }}$ It is however possible that part of the hydrogen stocked at the interface during the deposition can diffuse in its atomic form towards the Si substrate and participate hence to bulk defects passivation. On the opposite, $\mathrm{SiN}$ with a higher $\mathrm{N}$-content implies a denser material and the hydrogen contained in the film would diffuse in its atomic form towards the $\mathrm{SiN} / \mathrm{Si}$ interface. This is supported by $\mathrm{C}-\mathrm{V}$ results, which showed a decrease of $D_{i t}$ after annealing for samples with $R=7.7(n=2.03)$ and $\mathrm{R}=10(\mathrm{n}=1.98)$. As suggested by Sopori [4], atomic hydrogen diffusion would be assisted by defects and the high defect concentration at the SiN/Si interface would make easier the diffusion of this element towards the substrate. Moreover, we can assume that bulk defects reinforce this traps-driven hydrogen diffusion. This would explain why surface passivation changes are dependent of the region observed of the mc-Si substrate $(R=6)$ and why the relative $S_{\text {eff }}$ enhancement is more important for multicrystalline silicon substrates than for monocrystalline ones. Hence, all these results support that low refractive index $\mathrm{SiN}$ leads to the best $S_{\text {eff }}$ after the RTA process and that this can be attributed to an appropriate SiN structure and density. 


\section{Bulk Passivation}

Figure 10 shows the bulk lifetime $\tau_{\mathrm{b}}$ cartographies of the same mc-Si samples before and after the high temperature step. For the as-deposited samples (Figure 10.a), $\tau_{\mathrm{b}}$ is relatively high for the whole surface analyzed: the measured values lay between $100 \mu \mathrm{s}$ and $300 \mu \mathrm{s}$, which demonstrates the high quality of the mc-Si substrates used. However, the sample coated by the $\mathrm{Si}$-rich $\mathrm{SiN}(\mathrm{R}=2)$ presents a higher mean value of bulk lifetime $\left(\tau_{\mathrm{b}}=190 \mu \mathrm{s}\right)$. The two mc-Si substrates used were neighbouring wafers of a same ingot and we can assume that they present similar bulk structural properties. Hence, the observed differences could be attributed to hydrogen passivation of bulk defects during the PECVD process. Indeed, a higher $\mathrm{SiH}_{4}$ flow during the $\mathrm{SiN}$ deposition could provide higher H-radicals concentration in the plasma and these atoms could penetrate deep in the Si bulk substrate at the considered elaboration temperatures $\left(370^{\circ} \mathrm{C}\right)$.

The RTA process induced a clear enhancement of $\tau_{\mathrm{b}}$ for the mc-Si sample coated with " $\mathrm{N}$ rich" $\operatorname{SiN}(\mathrm{R}=6$ - Figure 10.b), the mean value going from $140 \mu \mathrm{s}$ to $210 \mu \mathrm{s}$. This value remained constant for the Si-rich SiN sample. However, a detailed observation of the corresponding cartography shows that bulk lifetime increased for a non negligible part of the sample. Thus, these results confirm that hydrogenation occurs during annealing and increases the minority carrier lifetime in the bulk of the silicon substrate. Furthermore, if we consider that the hydrogen contained in Si-rich $\mathrm{SiN}$ (less dense) is widely released in its $\mathrm{H}_{2}$ form, it appears that such molecules will not participate to the defect passivation. In this case, the increase of $\tau_{\mathrm{b}}$ could be due to neutralization of defects thanks to the atomic hydrogen initially stocked at the interface during $\mathrm{SiN}$ deposition. It could also be due to diffusion of hydrogen trapped in the bulk of the substrate itself, as some regions show a decrease of $\tau_{\mathrm{b}}$ after annealing. On the other hand, a high increase of $\tau_{b}$ is observed on the whole surface of the sample coated with the low refractive index SiN. This confirms that important atomic hydrogen diffusion occurs from the SiN towards the mc-Si substrate during the high temperature step, neutralizing the defects situated deeply in the sample. The hydrogen chemical bonding as well as the mass density of the SiN layer appears to be key parameters for an efficient substrate hydrogenation.

\section{Conclusion}

As it was recently highlighted by other research groups, the SiN mass density (and hence the Si-N bond density) appears to be a good indicator for optimum surface and bulk passivation after annealing. Indeed we showed a direct correlation between hydrogen desorption mechanism and the SiN Si-content. As the latter was correlated to the mass density, a clear relation was found with the SiN ability to release hydrogen in its atomic form, and hence to provide good final surface and bulk passivation. On the other hand, for asdeposited SiN films, a better surface and volume passivation is obtained thanks to Si-rich SiN. Here, a higher gas flow of silane during $\mathrm{SiN}$ deposition would lead to a plasma composition richer in hydrogen. The more "opened" structure of such Si-rich layers would facilitate the diffusion of H-radicals towards the silicon substrate during the short PECVD process. Hence, this would result in defect neutralization at the surface and deep in the bulk of the silicon substrate.

This study reveals thus that low refractive index SiN layers $(\mathrm{n} \sim 2-2.1)$ provide the best surface and bulk passivation properties after the RTA process. This is interesting for photovoltaic applications as such layers can be used efficiently as antireflective coating of mc-Si solar cells. Furthermore, $\mathrm{SiN}$ is of great interest for other photovoltaic structures. Indeed, current work is under investigation at INL-INSA to develop an optimized 
ARC/passivation layer for the front surface of Rear Contacted Cells (RCC). The fabrication of such solar cells does not involve a high temperature firing step. As surface passivation is a crucial issue in this case, a combination of low/high refractive index SiN layers could provide at the same time higher photon transmission through the optimization of the double antireflection coating, and higher surface passivation thanks to the Si-richer SiN layer in contact with the Si substrate. Moreover, investigation is under progress in order to apply $\mathrm{SiN}$ as passivation layer of the rear surface of conventional solar cells, which would be an alternative to the thick Al Back Surface Field (BSF) [55]. This issue has been a difficult one for a long time as the high positive charge density has been an important obstacle for proper solar cell operation (see e.g. [56]). However, recent works have showed that the combination of a local BSF and a SiN passivation layer applied to thin substrates can lead to good photovoltaic results [57]. Even if the physical reasons of such results stay unclear, this is encouraging for further investigation. In particular, as we have highlighted here that the SiN chemical structure is dependent on the deposition system and parameters, an interesting research task is the study of $\mathrm{SiN}$ deposited thanks to dilute silane. Indeed, as the deposition reactions and kinetics will be clearly different, the obtained material will present a distinct chemical structure in terms of mass density, hydrogen content and positive fixed charge density. Thus, it seems still possible to take advantage of the interesting optical and passivation properties of hydrogenated silicon nitride. 


\section{References}

[1] F. Duerinckx and J. Szulfcik. Defect passivation of industrial multicrystalline solar cells based on PECVD silicon nitride. Solar Energy Materials \& Solar Cells 2002, 72, pp. 231-246.

[2] C. Leguit et al. Low temperature surface passivation for silicon solar cells. Solar Energy Materials and Solar Cells 1996, 40, pp. 297-345.

[3] A.G. Aberle Overview on SiN Surface Passivation of crystalline silicon solar cells. Solar Energy Mat. \& Sol. Cells 2001, 65, pp. 239-248.

[4] B.L. Sopori, Y. Zhang, R. Reedy. H Diffusion for Impurity and Defect Passivation: A Physical Model for Solar Cell Processing. Proc. of the $29^{\text {th }}$ IEEE-Photovoltaic Specialists Conference, 2002, New Orleans (USA).

[5] T. Lauinger, A.G. Aberle and R. Hezel. Comparison of direct and remote PECVD silicon nitride films for low-temperature surface passivation of p-type crystalline silicon. Proc. of $14^{\text {th }}$ European. Photovoltaic Solar Energy Conference, 1997, Barcelona (Spain), p. 853.

[6] B. Sopori et al. A comprehensive model of hydrogen transport into a solar cell during silicon nitride processing for fire-through metallization. Proc. of the $31^{s t}$ Photovoltaic Specialists Conference, Jan. 2005, Orlando (USA), pp. $1039-1042$.

[7] V. Yelundur, A. Rohatgi, J.I. Hanoka, R. Reedy. Beneficial impact of low frequency pecvd $\mathrm{SiN}_{\mathrm{x}}: \mathrm{H}-$ induced hydrogenation in high efficiency string ribbon silicon solar cells. Proc. of $19^{\text {th }}$ European. Photovoltaic Solar Energy Conference 2004, Paris (France), pp. 951-954.

[8] J. Hong et al. Influence of the high-temperature "firing" step on high-rate plasma deposited silicon nitride films used as bulk passivating antireflection coatings on silicon solar cells. Journal of Vacuum Science and Technology B 2003, 21(5), pp. 2123-2132.

[9] H.F.W. Dekkers, L. Carnel, G. Beaucarne and W. Beyer. Diffusion mechanism of hydrogen through PECVD $\mathrm{SiN}_{\mathrm{x}}: \mathrm{H}$ for a fast defect passivation of mc-Si solar cells. Proceedings of the $20^{\text {th }}$ European Photovoltaic Solar Energy Conference, June 2005, Barcelona (Spain).

[10] W.D. Eades and R.M. Swanson. Calculation of surface generation and recombination velocities at the Si-SiO ${ }_{2}$ interface. Journal of Applied Physics 1985, 58, p. 4267.

[11] A. Cuevas, M.J. Kerr and J. Schmidt. Passivation of crystalline silicon using silicon nitride. $3^{\text {rd }}$ World Conference on Photovoltaic Energy Conversion, May 2003, Osaka (Japan).

[12] H. Mäckel and R. Lüdemann. Detailed study of the composition of hydrogenated $\mathrm{SiN}_{\mathrm{x}}$ layers for highquality silicon surface passivation. Journal of Applied Physics 2002, 92(5), pp. 2602-2609.

[13] B. Sopori. Dielectric films for Si solar cell applications. Journal of Electronic Materials, 2005, 34(5), pp. 564-570.

[14] J.Y. Lee, J. Divker, S. Rein and S.W. Glunz. Investigation of various surface passivation layers using oxide/nitride stacks of silicon solar cells. Proceedings of the $3^{\text {rd }}$ World Conference on Photovoltaic Energy Conversion, 2003, Osaka (Japan).

[15] A.W. Weeber, H.C. Rieffe, I.G.Romijn, W.C. Sinke, W.J. Soppe. The fundamental properties of $\mathrm{SiN}_{\mathrm{x}}: \mathrm{H}$ that determine its passivating qualities. Proc. of the $31^{\text {st }}$ Photovoltaic Specialists Conference 2005, Orlando (USA), pp. 1043-1046.

[16] W.A. Lanford and M.J. Rand. The hydrogen content of plasma-deposited silicon nitride. Journal of Applied Physics 1978, 49(4), pp. 2473-2477.

[17] J. Hong et al. Structural film characteristics related to the passivation properties of high-rate $(>0.5 \mathrm{~nm} / \mathrm{s})$ plasma deposited a-SiN $\mathrm{x}: \mathrm{H}$. Proc. of the $3^{\text {rd }}$ World Conf. on Photovoltaic Energy Conversion 2003, Osaka (Japan) , p. 1158.

[18] I. Romijn et al. $\mathrm{SiN}_{\mathrm{x}}: \mathrm{H}$ passivation: How to obtain the maximum efficiency for mc-Si solar cells. Workshop on the fundamentals of $a-S_{i} N_{x}: H$ in industrial solar cell processing, $3^{\text {rd }}$ Nov. 2005, IMEC, Leuven (Belgium). All the presentations are available on-line :

<http://www.ipcrystalclear.info/Paginas/Overige\%20webpaginas/Programme\%20and\%20presentations $\% 20 \mathrm{SiNx} \% 20$ fundamentals\%20workshop.aspx > (last consultation 23/05/08)

[19] I.G.Romijn, W.J. Soppe, H.C. Rieffe, A.R. Burgers, A.W. Weeber. Passivating mc-Si solar cells using SiNx:H: Magic or Physics. Proc. $20^{\text {th }}$ European Photovoltaic Solar Energy Conf. 2005, Barcelona (Spain), pp. 1352-1355. 
[20] A. Cuevas, F. Chen, J. Tan, H. Mäckel, S. Winderbaum and K. Roth. FTIR analysis of microwave excited PECVD silicon nitride. Proc. of the $4^{\text {th }}$ World Conf. on Photovoltaic Energy Conversion 2006, Waikoloa (USA), pp. 1148-1151.

[21] F. Chen, I. Romijn, A. Weeber, J. Tan, B. Hallam, and J. Cotter. Relationship between PECVD silicon nitride film composition and surface and edge passivation. Proc. of the $22^{\text {nd }}$ European Photovoltaic Solar Energy Conference 2007, Milan (Italy), pp. 1053-1060.

[22] G.E. JELLISON and F.A. MODINE. Parameterization of the optical functions of amorphous materials in the interband region. Applied Physics Letters 1996, 69(3), pp.371-373, 2137.

[23] G.K. REEVES and H.B. HARRISON. Obtaining the specific contact resistance from transmission line model measurements. Electron Device Letters 1982, 3(5), pp. 111-113.

[24] E.H. Nicollian and J.R. Brews. MOS Physics and Technology. New-York: Wiley-Interscience 1982.

[25] R.A. Sinton and A. Cuevas. Contactless determination of current-voltage characteristics and minoritycarrier lifetimes in semiconductors from quasi-steady-state photoconductance data. Applied Physics Letters 1996, 69(17), pp. 2510-2512.

[26] A. Cuevas and D. Macdonald. Measuring and interpreting the lifetime of silicon wafers. Solar Energy 2004, 76(1-3), pp. 255-262.

[27] F. Schuurmans. Surface passivation of silicon by PECVD silicon nitride. PhD Thesis 1998, University of Utrecht (The Netherlands), 134 p.

[28] Palais O. And Arcari A. Contactless measurement of bulk lifetime and surface recombination velocity in silicon wafers. Journal of Applied Physics 2003, 93(8), pp. 4686-4690.

[29] A. Cuevas, M. Stocks, D. Mcdonald, M. Kerr and C. Samundsett. Recombination and trapping in multicrystalline silicon. IEEE Transactions on Electron Devices 1999, 46(10), pp. 2026-2034.

[30] H.R. Philipp. Silicon nitride $\left(\mathrm{Si}_{3} \mathrm{~N}_{4}\right)$ (Noncrystalline). In: Handbook of optical constants of solids 1985, vol. 1, Ed. E.D. PALIK. New-York, USA: Academic Press, pp. 771-774.

[31] S. De Wolf, G. Agostinelli, G. Beaucarne and P. Vitanov. Influence of stoichiometry of direct plasmaenhanced chemical vapor deposited $\mathrm{SiN}_{\mathrm{x}}$ films and silicon substrate roughness on surface passivation. Journal of Applied Physics 2005, 97, p. 063303.

[32] J-F.Lelièvre et al. Comparative study of structural and optical properties of silicon nitride $\mathrm{SiN}_{\mathrm{x}}: \mathrm{H}$ deposited by PECVD. Proc. of the $20^{\text {th }}$ European Photovoltaic Solar Energy Conference 2005, Barcelona (Spain), pp. 1142-1145

[33] A. Dollet, J. P. Couderc and B. Despax. Analysis and numerical modelling of silicon nitride deposition in a plasma-enhanced chemical vapor deposition reactor. Part I: bidimensional modelling. Plasma Sources Science and Technology 1995, 4, pp. 94-106.

[34] H. Caquineau, G. Dupont, B. Despax and J.P. Couderc. Reactor modelling for radio frequency plasma deposition of $\mathrm{SiN}_{\mathrm{x}} \mathrm{H}_{\mathrm{y}}$ : Comparison between two reactor designs. Journal of Vacuum Science \& Technology A 1996, 14(4), pp. 2071-2082.

[35] J-F. Lelièvre, H. Rodriguez, E. Fourmond, S. Quoizola, M. Lipinski, D. Araujo, G. Bremond, M. Lemiti. Electro-optical characterisation for the control of silicon nanocrystals embedded in $\mathrm{SiN}_{\mathrm{x}}: \mathrm{H}$ films. Physica Status Solidi (c) 2007, 4(4), pp. 1554-1559.

[36] J-F. Lelièvre et al. Evidence of intrinsic silicon nanostructures formation in SiN matrix deposited by various low temperature CVD techniques. Physica Status Solidi (c) 2007, 4(4), pp. 1401-1405.

[37] M.A. Green et al. Progress with all-silicon tandem cells based on silicon quantum dots in a dielectric matrix. Proc. of $21^{\text {st }}$ European. Photovoltaic Solar Energy Conference. 2006, Dresden (Germany), pp. $10-14$.

[38] V.A. Gritsenko, K.S. Zhuravlev, A.D. Milov, H. Wong, R.W.M. Kwok, J.B. Xu. Silicon dots/clusters in silicon nitride: photoluminescence and electron spin resonance. Thin Solid Films 1999, 353, pp. 20-24.

[39] H.R. Philipp. Optical Properties of Silicon Nitride. Journal of the Electrochemical Society 1973, 120, p. 295.

[40] G.M. Ingo, N. Zacchetti, D.Della Sala and C. Coluzza. X-ray photoelectrons spectroscopy investigation on the chemical structure of amorphous silicon nitride $\left(\mathrm{a}-\mathrm{SiN}_{\mathrm{x}}\right)$. Journal of Vacuum Science and Technology 1989, 7(5), pp.3048-3055.

[41] E. Bustarret et al. Configurational statistics in a- $\mathrm{Si}_{\mathrm{x}} \mathrm{N}_{\mathrm{y}} \mathrm{H}_{\mathrm{z}}$ alloys: A quantitative bonding analysis. Physical Review B 1998, 38(12), pp. 8171-8183.

[42] Stefan Dauwe. Low temperature surface passivation of crystalline silicon and its application to the rear side of solar cells. PhD Thesis 2004, Hannover Universität (Germany), page 76. 
[43] J-F. Lelièvre, A. Kaminski, J-P. Boyeaux, R. Monna, M. Lemiti. Optical properties of PECVD and

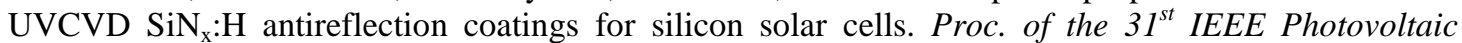
Specialists Conference 2005, Orlando (USA), pp. 1111-1114.

[44] J-F.Lelièvre et al. Correlation of optical and photoluminescence properties in amorphous $\mathrm{SiN}_{\mathrm{x}}: \mathrm{H}$ thin films deposited by PECVD or UVCVD. Thin Solid Films 2006, 511-512, p. 103.

[45] G. Morello. Hydrogen content of amorphous PECVD $\operatorname{SiN}_{\mathrm{x}}: \mathrm{H}$ films by infrared spectroscopy and hydrogen forward scattering results. Journal of Non-Crystalline Solids 1995, 187, pp. 308-312.

[46] V. Verlaan et al. Hydrogen evolution in hot-wire deposited SiN with calibrated FTIR proportionality constants. Workshop on the fundamentals of a-SiN ${ }_{x}: H$ in industrial solar cell processing, $3^{\text {rd }}$ Nov. 2005, IMEC, Leuven, Belgium. Presentation available on-line (see Ref. 18)

[47] I.V. Afanasyev-Charkin et al. Amorphous silicon nitride films of different composition deposited at room temperature by pulsed glow discharge plasma immersion ion implantation and deposition. Journal of Vacuum Science and Technology 2004, 22(6), pp. 2342-2346.

[48] Z. Yin and F.W. Smith. Optical dielectric function and infrared absorption of hydrogenated amorphous silicon nitride films: Experimental results and effective-medium-approximation analysis. Physical Review B 1990, 42(6), pp. 3666-3675.

[49] F. Giorgis et al. Optical, structural and electrical properties of device-quality hydrogenated amorphous silicon nitrogen films deposited by plasma-enhanced chemical vapour deposition. Philosophical Magazine B 1998, 77(4), pp. 925-944.

[50] F. Jiang, M. Stavola, A. Rohatgi, D. Kim, J. Holt, H. Atwater, J. Kalejs. Hydrogenation of Si from $\mathrm{SiN}_{\mathrm{x}}(\mathrm{H})$ films: Characterization of $\mathrm{H}$ introduced into the Si. Applied Physics Letters 2003, 83(5), pp.931-933.

[51] J. Robertson, W.L. Warren and J. Kanicki. Nature of Si and N dangling bonds in silicon nitride. Journal of Non-Crystalline Solids 1995, 187, pp. 297-300.

[52] J. Schmidt and A.G. Aberle. Carrier recombination at silicon-silicon nitride interfaces fabricated by plasma enhanced chemical vapor deposition. Journal of Applied Physics 1998, 85(7), pp. 3626-3633.

[53] J. Schmidt and S. Dauwe. Surface Passivation of Silicon Solar Cells using SiNx : The Effect of Space Charge Recombination. Workshop on the fundamentals of a-SiN $N_{x} H$ in industrial solar cell processing, $3^{\text {rd }}$ Nov. 2005, IMEC, Leuven, Belgium. Presentation available on-line (see Ref. 18)

[54] J. Schmidt and M. Kerr. Highest-quality surface passivation of low-resistivity p-type silicon using stoichiometric PECVD silicon nitride. Solar Energy \& Solar Cells 2001, 65, pp. 585-591.

[55] J. Dupuis, E. Fourmond, O. Nichiporuk, F. Gibaja, M. Lemiti. Rear passivation schemes and their applications in industrial silicon solar cells, to be presented in the $23^{\text {rd }}$ European Photovoltaic Solar Energy Conference, 2008, Valencia (Spain).

[56] S. Dauwe, L. Mittelstädt, A. Metz and R. Hezel. Loss mechanisms in silicon nitride rear surface passivation for silicon solar cells. Proc. of the $17^{\text {th }}$ European Photovoltaic Solar Energy Conference, 2001, Munich (Germany).

[57] L. Janßen, M. Rinio, D. Borchert, H. Windgassen, D.L. Batzner and H. Kurz. Thin bifacial multicrystalline silicon solar cells for industrial production. Proc. of $21^{\text {st }}$ European. Photovoltaic Solar Energy Conference, 2006, Dresden (Germany). 


\section{Tables}

Table 1: Effective lifetime $\tau_{\text {eff }}$ and surface recombination velocity $S_{\text {eff }}$ of $n$ - and p-type FZ cSi samples coated with different as-deposited $\operatorname{SiN}\left(\Delta \mathrm{n}=7.10^{14} \mathrm{~cm}^{-3}\right)$.

\begin{tabular}{|c|c|c|c|c|c|c|}
\cline { 3 - 7 } \multicolumn{2}{c}{} & \multicolumn{2}{c|}{$\boldsymbol{\tau}_{\text {eff }}(\boldsymbol{\mu s})$} & \multicolumn{2}{c|}{$\mathbf{S}_{\text {eff }}\left(\mathbf{c m}_{\mathbf{s}} \mathbf{- 1}^{-1}\right)$} \\
\hline $\mathbf{R =} \mathbf{N H}_{\mathbf{3}} / \mathbf{S i H}_{\mathbf{4}}$ & $\mathbf{x}=\mathbf{N} / \mathbf{S i}$ & $\mathbf{n}(\mathbf{6 0 5} \mathbf{~ n m})$ & $\mathbf{n}$ & $\mathbf{p}$ & $\mathbf{n}$ & $\mathbf{p}$ \\
\hline $\mathbf{2}$ & 0.35 & 2.98 & 3620 & 1090 & 4 & 14 \\
\hline $\mathbf{2 . 5}$ & 0.42 & 2.69 & 1170 & 437 & 13 & 34 \\
\hline $\mathbf{3 . 5}$ & 0.49 & 2.47 & 722 & 233 & 21 & 65 \\
\hline $\mathbf{6}$ & 0.71 & 2.08 & 531 & 231 & 28 & 65 \\
\hline $\mathbf{7 . 7}$ & 0.78 & 2.03 & 456 & 221 & 33 & 68 \\
\hline $\mathbf{1 0}$ & 0.81 & 1.98 & 400 & 202 & 38 & 75 \\
\hline
\end{tabular}




\section{Figures}

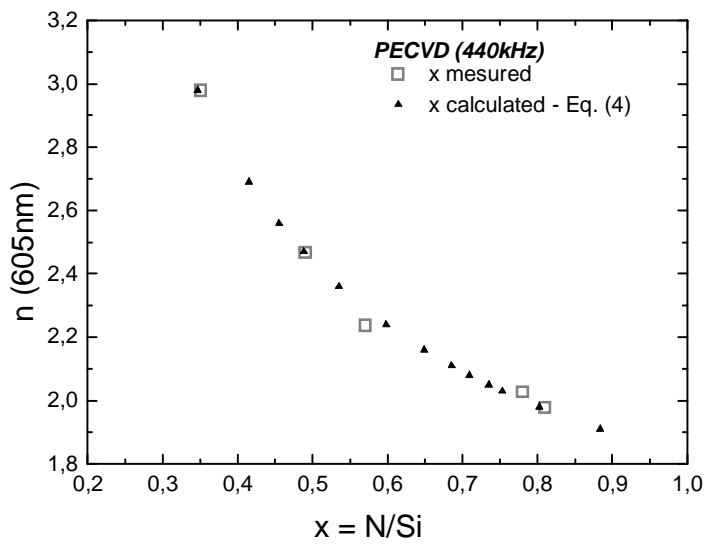

Figure 1: Evolution of the refractive index $\mathrm{n}(605 \mathrm{~nm})$ according to the SiN stoichiometry $\mathrm{x}=\mathrm{N} / \mathrm{Si}$ (measured values by XPS and estimated values thanks to Eq. 4) .

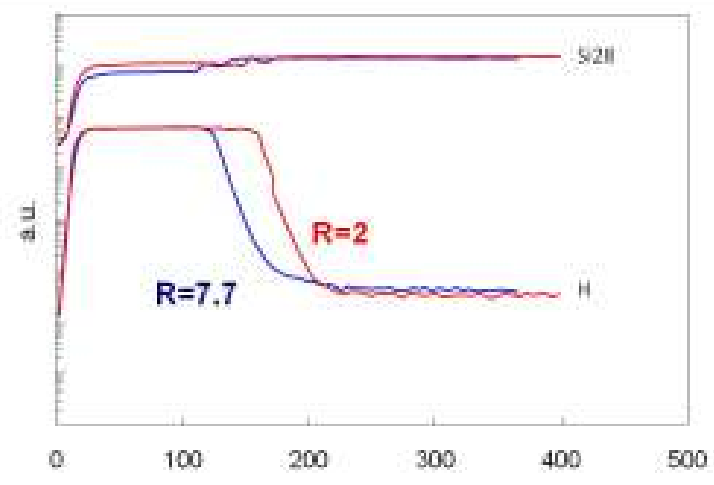

Figure 2: Comparison of the hydrogen profile obtained by SIMS for two distinct SiN compositions $(\mathrm{R}=2 / \mathrm{n}=2.98$ and $\mathrm{R}=7.7 / \mathrm{n}=2.03)$. The respective silicon signals ( $\mathrm{Si} 28)$ were adjusted at the same level in the Si substrate.

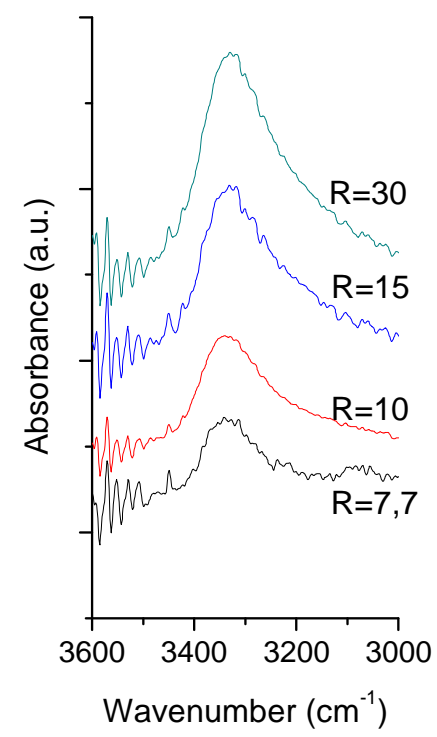

Figure 3: Evolution of the N-H stretching absorption band measured by FTIR for different SiN stoichiometries $\left(\mathrm{R}=\mathrm{NH}_{3} / \mathrm{SiH}_{4}\right)$. 


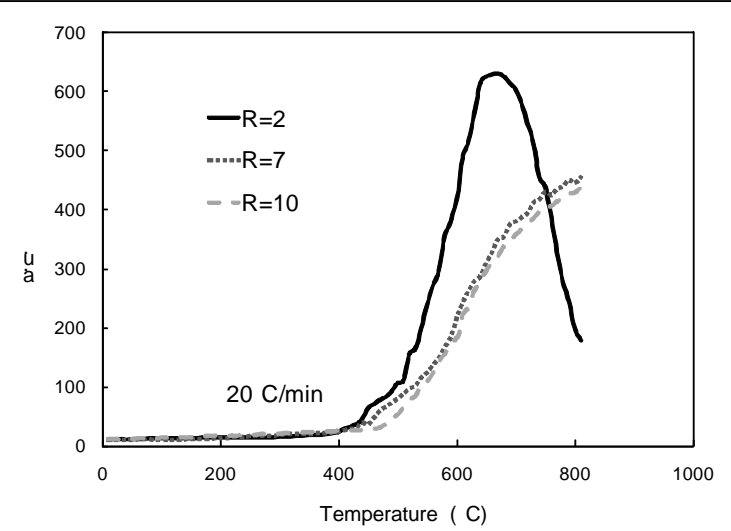

Figure 4: Hydrogen desorption profile according to the temperature obtained by TPD for three different $\mathrm{SiN}$ coatings $\left(\mathrm{R}=\mathrm{NH}_{3} / \mathrm{SiH}_{4}\right)$.

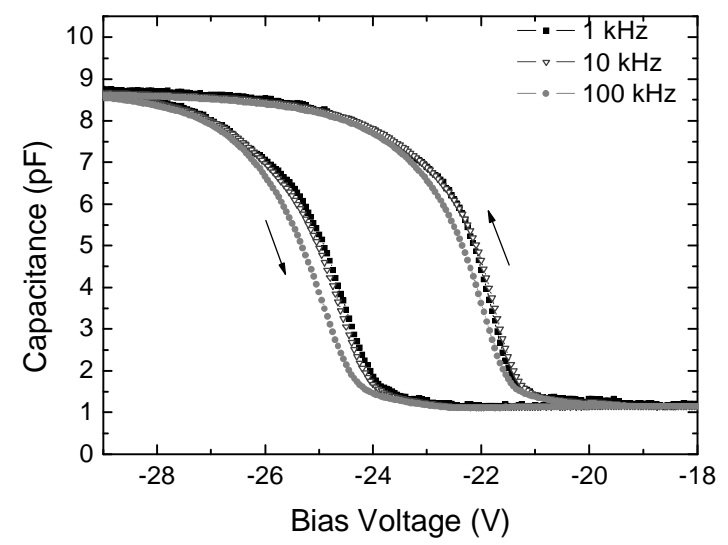

Figure 5: Typical Capacitance-Voltage curve obtained at different frequencies for the sample with $\mathrm{R}=10(\mathrm{n}=1.98)$.

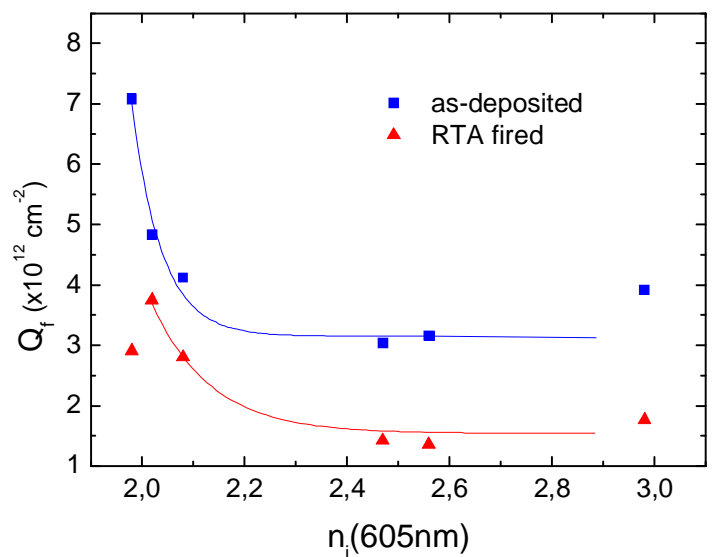

Figure 6: Fixed charge density $\mathrm{Q}_{\mathrm{f}}$ before and after annealing according to the initial refractive index $\mathrm{n}_{\mathrm{i}}(605 \mathrm{~nm})$. The curves are to guide the eye. 


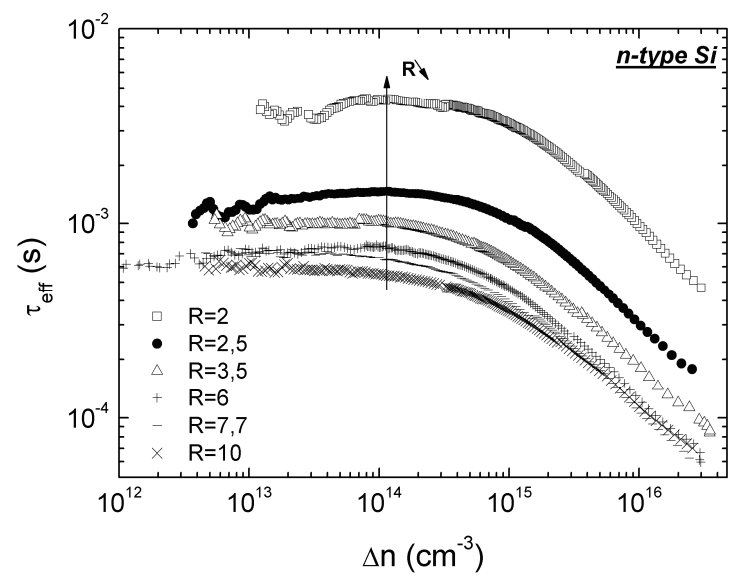

Figure 7: Effective lifetime $\tau_{\text {eff }}$ according to the injection level $\Delta \mathrm{n}$ for $\mathrm{n}$-type samples coated with $\mathrm{SiN}$ of different stoichiometries (indicated by the gas flow ratio $\mathrm{R}=\mathrm{NH}_{3} / \mathrm{SiH}_{4}$ ).

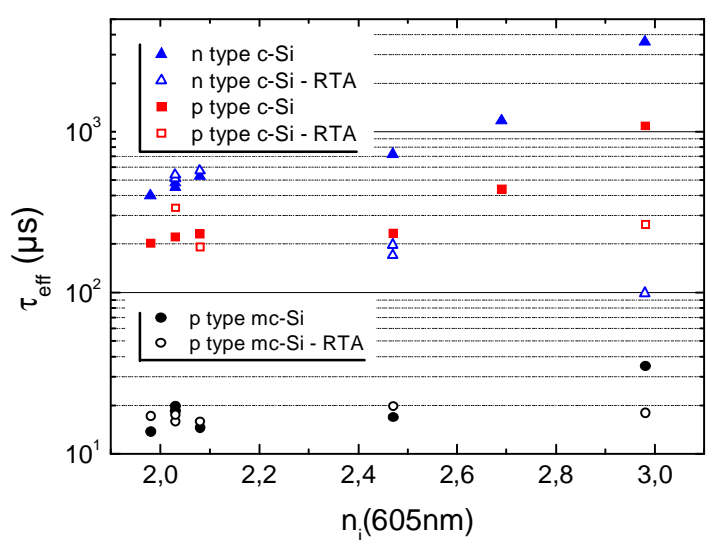

Figure 8: Effective lifetime $\tau_{\text {eff }}\left(\Delta \mathrm{n}=7.10^{14} \mathrm{~cm}^{-3}\right)$ before and after annealing according to the SiN initial refractive index $\mathrm{n}_{\mathrm{i}}(605 \mathrm{~nm})$. 

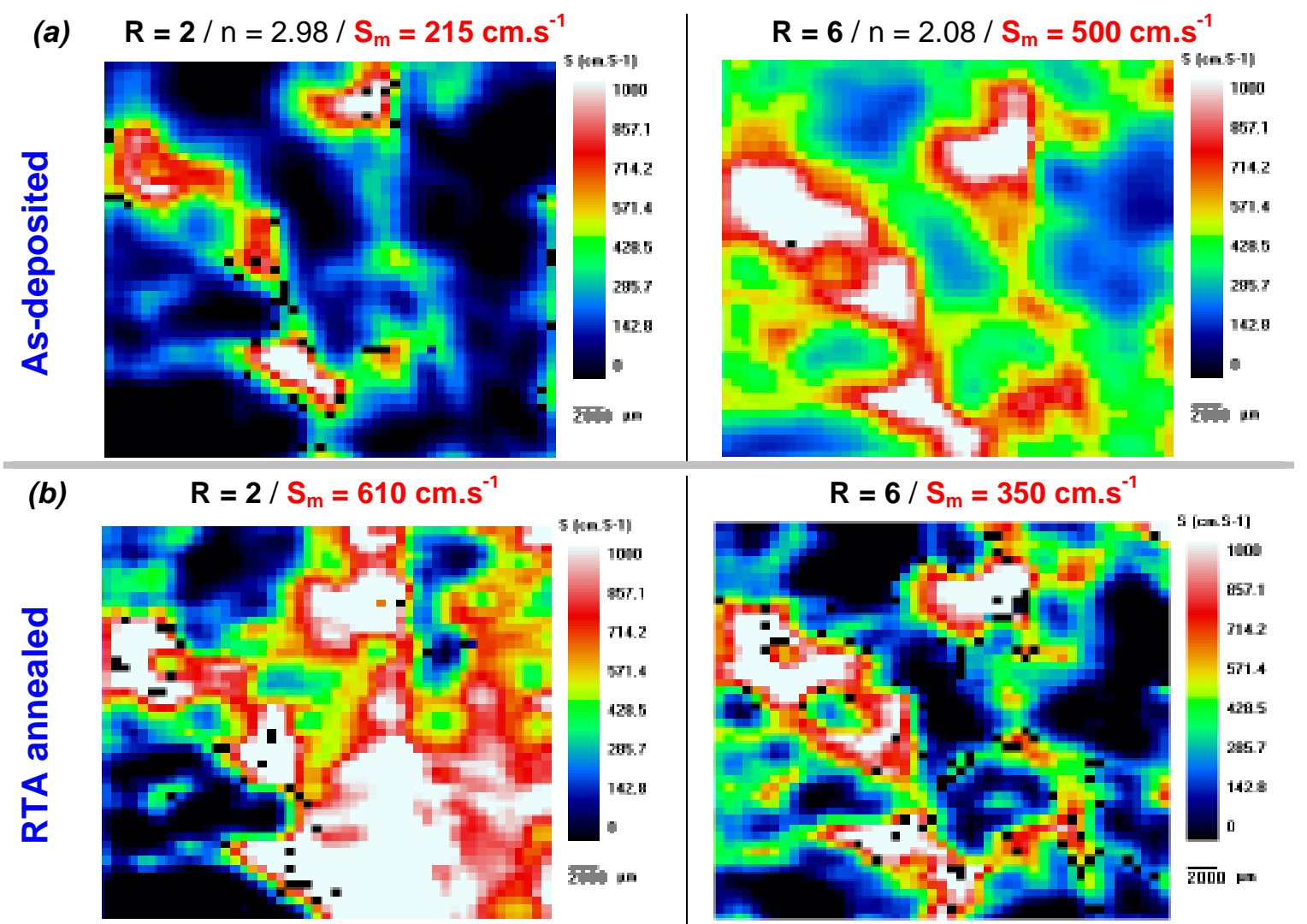

Figure 9: Surface recombination velocity $S_{\text {eff }}$ cartographies of p-type mc-Si samples (a) after $\underline{\text { SiN deposition and (b) after RTA firing }\left(S_{\mathrm{m}} \text { correspond to average values). }\right.}$
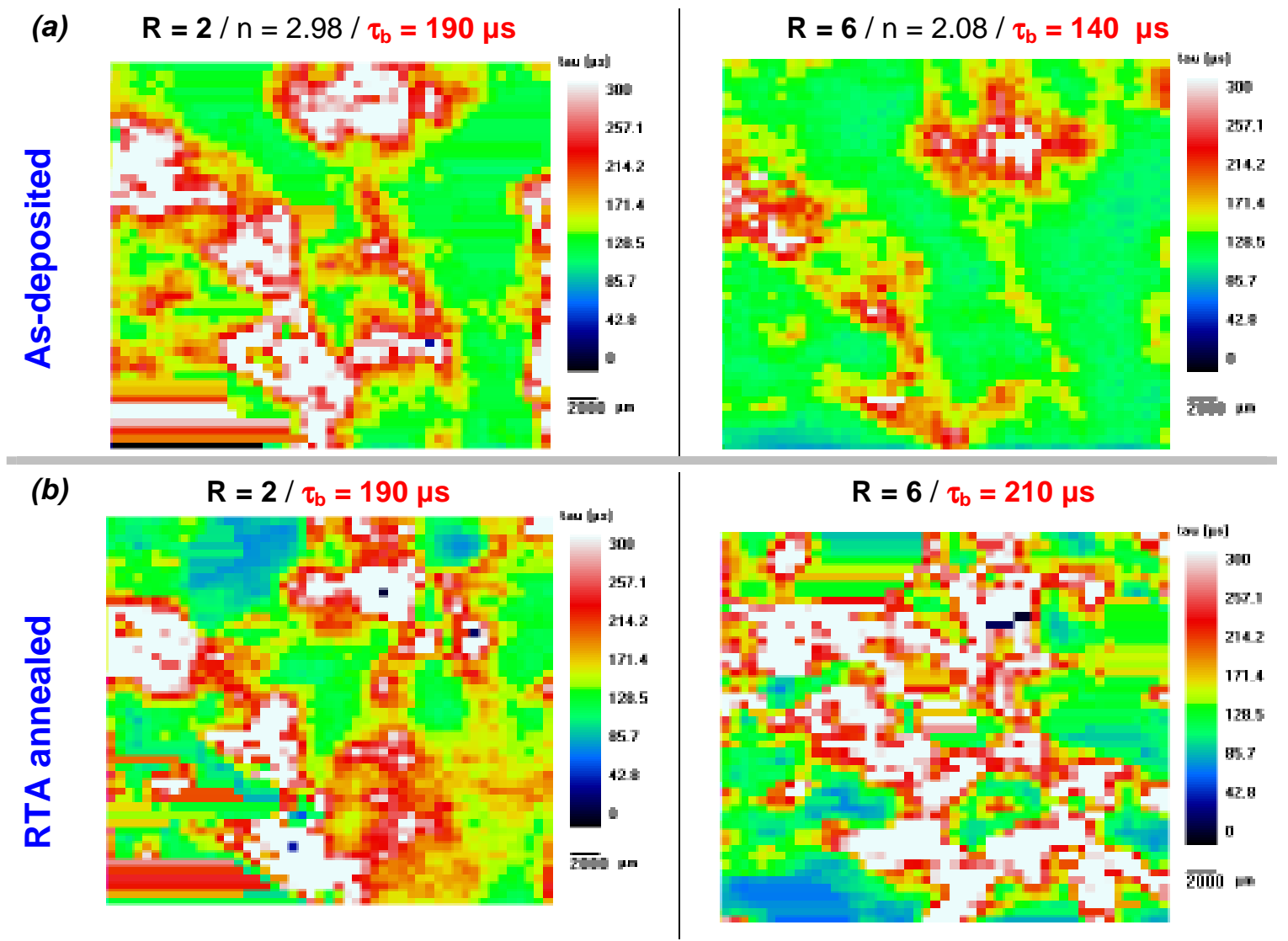

Figure 10: Bulk lifetime $\tau_{\mathrm{b}}$ cartographies of p-type mc-Si samples (a) after $\mathrm{SiN}$ deposition and (b) after RTA firing (The indicated $\tau_{\mathrm{b}}$ values correspond to average values). The lines 
situated in the lower left angle are measurement artefacts and should not be taken into account. 